\title{
Experimental investigations and analysis on churning losses of splash lubricated spiral bevel gears
}

\author{
S. Laruelle ${ }^{1,2,3}$, C. Fossier ${ }^{1,2}$, C. Changenet ${ }^{2, *}$, F. Ville ${ }^{1}$, and S. Koechlin ${ }^{3}$ \\ ${ }^{1}$ Univ. Lyon, INSA-Lyon, LaMCoS, UMR 5259, Villeurbanne, France \\ ${ }^{2}$ Univ. Lyon, ECAM Lyon, INSA-Lyon, LabECAM, Lyon, France \\ ${ }^{3}$ Leroy Somer, Emerson Corp., Angoulême, France
}

Received: 19 October 2016 / Accepted: 24 January 2017

\begin{abstract}
Churning losses are a complex phenomenon which generates significant power losses when considering splash lubrication of gear units. However, only few works deal with bevel gears dipped lubrication losses. The objective of this study is to provide a wide variety of experimental tests on churning losses, especially getting interested in geometry of spiral bevel gears influence. A specific test rig was used in order to study a single spiral bevel gear partially immersed in an oil bath. Experiments have been conducted for several operating conditions in terms of speeds, lubricants, temperatures and gear geometries to study their impact on splash lubrication power losses. These experimental results are compared with the predictions from various literature sources. As the results did not agree well with the predictions for all operating conditions, an extended equation derived from previous works is introduced to estimate churning losses of bevel gears.
\end{abstract}

Keywords: spiral bevel gears / churning / lubrication / power losses

\section{Introduction}

In a development stage, it is important to predict the behaviour of industrial gear units. System efficiency is estimated through the evaluation of power losses. Industrial gear units are often dipped lubricated in the case of low to medium speed geared transmission. In these cases, churning losses are an important part of no load losses, as shown in studies on both cylindrical [1] or hypoid gears [2]. An accurate evaluation of these dissipation sources is needed. Theoretical prediction of churning losses is complex to solve since the fluid mechanics problem is related to a free surface and a two-phase flow. Extensive experimental measurements of churning losses for different operating conditions can lead to empirical or semi-empirical formulas. Analytical formulas allow users to point out the influencing parameters leading to design guidelines.

The drag torque due to the rotation of discs submerged in a fluid has been theoretically analysed by Soo and Princeton [3], Daily and Nece [4], or Mann and Marston [5]. In the case of gears, different experimental studies have been conducted with the aim of developing empirical relationships to quantify churning losses. As an example, some tests have been conducted with high viscosity oils and low rotational speeds by Terekhov [6] for spur cylindrical

\footnotetext{
* e-mail: christophe.changenet@ecam.fr
}

gears or Kolekar et al. [2] for hypoid gears. Further extension of Terekhov work was done by Lauster and Boos [7], who applied this approach on a real truck transmission. Boness [8] conducted experiments on discs and gears in low viscosity fluids and developed an associated relationship. Based on previous works performed by Walter [9] and Mauz [10] on no-load gear losses for splash lubrication, Höhn et al. [11,12] also proposed a model of spur gear churning based on a single flow regime. From this wide variety of formulas, Luke and Olver [1] have shown that deviations on power loss calculations might be significant.

Recently churning power loss expressions are extended to a wider domain. To this end, fluid mechanics models are developed to estimate churning behaviour, as presented by Seetharaman and Kahraman [13], who worked on cylindrical gear pairs subject to churning and windage. Arisawa et al. [14] also referred to fluid mechanics to simulate churning in aero engine transmissions. Further works are also done concerning analytical formulations to quantify churning power losses, for example, considering multiple flow regimes [15]. The inertia run down method is used to obtain experimental results. Another methodology based on experimental measurements was done by Changenet et al. [16,17], who used dimensional analysis to propose a model for cylindrical gears. Then Marques et al. [18] worked on extending previous formulas to a wider range of application showing the shape influence of the oil sump. It can be also noticed that several studies [19-21] used 


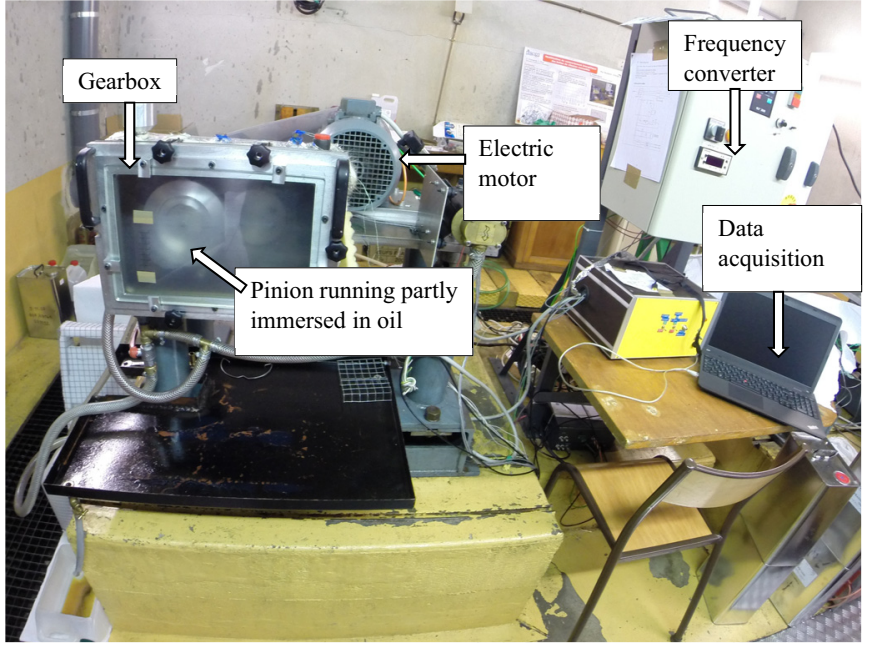

Fig. 1. Test rig.

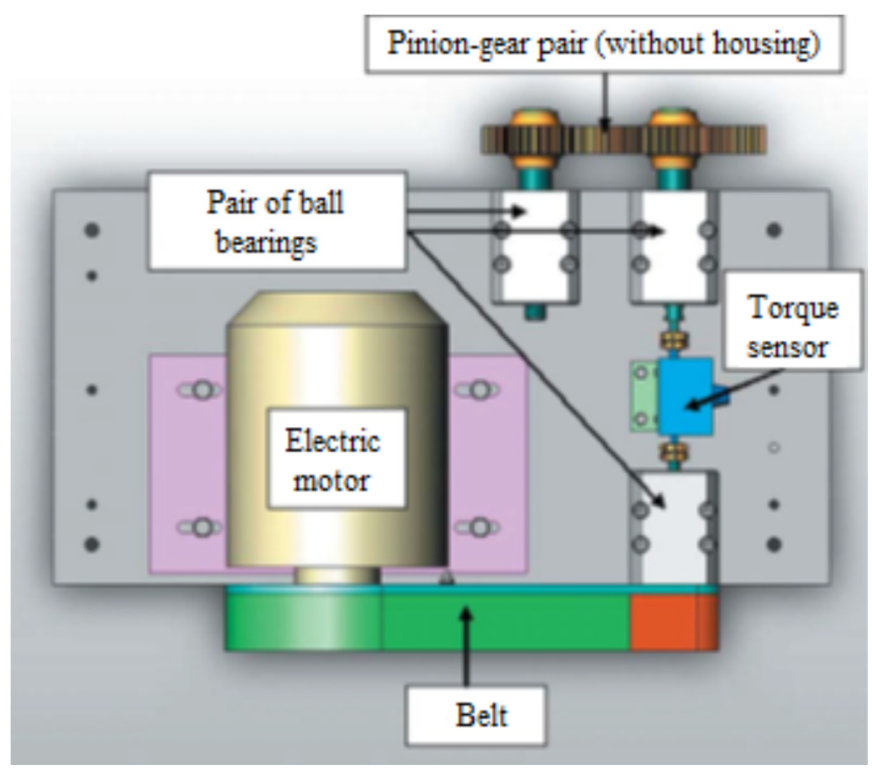

Fig. 2. Description scheme of the test rig.

Table 1. Gears dimensions.

\begin{tabular}{lllllll}
\hline & Gear 1 & Gear 2 & Gear 3 & Gear 4 & Cone 1 & Cone 2 \\
\hline External diameter [mm] & 157 & 130 & 188 & 154 & 157 & 160 \\
Number of teeth & 41 & 37 & 41 & 37 & 0 & 0 \\
Face angle ['] & 72.4 & 58.1 & 72.4 & 58.1 & 72.4 & 58.1 \\
Module [mm] & 2.6 & 2.4 & 3.1 & 2.9 & - & - \\
Face width [mm] & 27 & 24.5 & 32 & 27.5 & 27 & 24.5 \\
Width [mm] & 22 & 27 & 30 & 30 & 22 & 27 \\
Pressure angle ['] & 20 & 20 & 20 & 20 & - & - \\
Mean spiral angle [ ${ }^{\circ}$ ] & 35 & 35 & 35 & 35 & - & - \\
\hline
\end{tabular}

numerical simulations (computational fluid dynamics code) to predict load independent power losses and more specifically the churning ones.

However, even if extensive studies are available on cylindrical gears, it appears from this state of art that very little experimental data concerning churning losses generated by bevel gears are available in literature. Moreover, different relationships are proposed to estimate this source of dissipation for hypoid or spiral bevel gears: technical reports ISO/TR 14179-1 [22] and ISO/TR 14179-2 [23], or Jeon works [24] (details are given in Appendix A).

To extend previous studies on spiral bevel gear churning losses, a specific test rig has been used which is described in Section 1. Extensive experiments were conducted and the obtained results are presented in Section 2. The influence of gear geometry on churning losses is highlighted. Several experimental results are compared with the predictions from the above-mentioned literature sources. As the comparisons are not satisfactory for all operating conditions, an extended equation derived from Jeon's approach is introduced to estimate churning losses of bevel gears.

\section{Test rig}

A precise description of the test rig shown in Figure 1 is available in [16]; only the main features are exposed in this paper.

The test rig allows measuring the lubricant temperature and the churning torque of an isolated gear or of a couple of gears as detailed in Figure 2. The gear is driven in rotation by an electric motor. The resisting torque is directly measured by a strain-gauged, temperature compensated, contactless sensor (FGP-CD1140) of accuracy $\pm 0.002 \mathrm{Nm}$, a sensitivity shift of $0.009 \%{ }^{\circ} \mathrm{C}^{-1}$, and a zero shift of $0.0004 \mathrm{~N} \mathrm{~m}^{\circ} \mathrm{C}^{-1}$ in the $5-45^{\circ} \mathrm{C}$ temperature range. The pinion is supported by two ball bearings and their contribution has to be isolated from the total resisting torque. To do that, the bearing drag torque has been experimentally determined as a function of speed by removing the gear from the test rig. For example, it has been found that a pair of bearings generates a drag torque of $0.045 \mathrm{Nm}$ at $7000 \mathrm{rpm}$, which is a significant value compared to the accuracy of the torque sensor. A pulse 


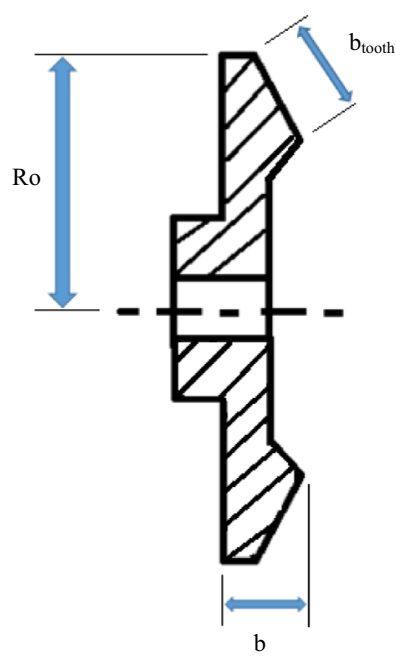

\#1 and \#3

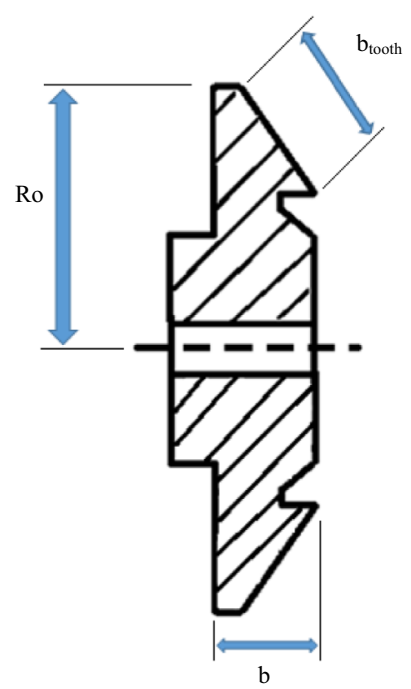

$\# 2$ and \#4

Fig. 3. Typical gear geometries.

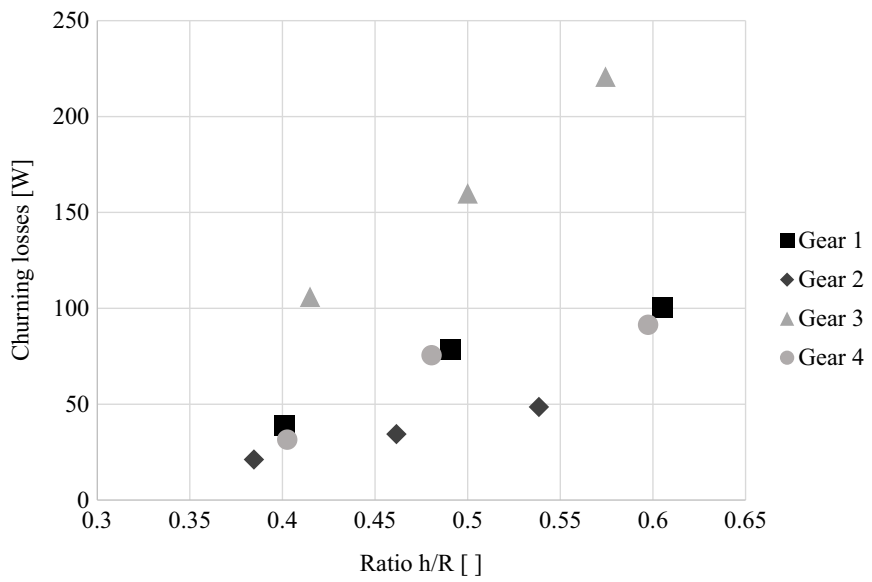

Fig. 4. Influence of immersion on churning losses (oil C, $\left.2000 \mathrm{rpm}, 40^{\circ} \mathrm{C}\right)$.

Table 2. Oil data.

\begin{tabular}{lllll}
\hline Oil name & Oil A & Oil B & Oil C & Oil D \\
\hline Viscosity @ $40^{\circ} \mathrm{C}$ & $220 \mathrm{cSt}$ & $35 \mathrm{cSt}$ & $45.1 \mathrm{cSt}$ & $120 \mathrm{cSt}$ \\
Viscosity @ $100^{\circ} \mathrm{C}$ & $19 \mathrm{cSt}$ & $7.5 \mathrm{cSt}$ & $7.7 \mathrm{cSt}$ & $16 \mathrm{cSt}$ \\
Density @ $15^{\circ} \mathrm{C}$ & $895 \mathrm{~kg} \mathrm{~m}^{-3}$ & $870 \mathrm{~kg} \mathrm{~m}^{-3}$ & $885 \mathrm{~kg} \mathrm{~m}^{-3}$ & $860 \mathrm{~kg} \mathrm{~m}^{-3}$ \\
Oil type & Mineral & Mineral & Mineral & Synthetic \\
\hline
\end{tabular}

counter in the torque sensor ensures the speed measurement. The oil sump is a parallelepiped with a Plexiglas face to observe the flow around gears. The oil level can be modified. The oil bath temperature is controlled and measured by thermocouples. Several heating covers are installed on the external faces of the housing. The maximum deviation between two repetitions of the same test is equal to $5 \%$.

Four bevel gear geometries are available for these tests. Geometrical dimensions are given in Table 1. Two different types of macro-geometries were tested (Fig. 3). One shape consists in a high face angle and a narrow width, and the other one has a smaller face angle and a larger width. In order to study the influence of tooth geometry on churning losses, it can be noted that two smooth cones have also been manufactured (Tab. 1). As far as lubricants are concerned, four different oils were used. Their characteristics are resumed in Table 2 .

As shown by Leprince et al. [25], oil aeration, which is defined as the volumetric fraction of air in the lubricant, is negligible when it is less than approximately $10 \%$. With the same methodology as the one used in the above-mentioned work on cylindrical gears, aeration measurements have confirmed this observation for this specific study on spiral bevel gears: smaller than $7 \%$ on the tested domain.

\section{Results}

Experiments were performed for different operating conditions (oil properties - viscosity and density -, rotational speed, gear immersion level) and different spiral bevel gear geometries (diameter, width, face width, face angle, tooth number, module).

Measurements for different spiral bevel gears as a function of their relative immersion depth are shown in Figure 4. It clearly appears that this parameter is a first order influent one on churning losses. Considering rotational speed, it can be noticed that the losses are proportional to $N^{1.7}$ (see Fig. 5, a similar relative immersion depth of 0.5 was used for the tested gears). For higher rotational speeds, a drag torque decrease is observed, as presented in Figure 6 and noticed by Jeon [24]. Two types of regime were observed between 1000 and $4000 \mathrm{rpm}$ : (i) for the first regime, the oil is projected and the torque increases with speed; (ii) for the second one, which corresponds to higher rotational speeds, the torque decreases. The second regime can be interpreted as follows: centrifugal effects generated by the rotating gears become significant and induced a reduction in immersion depth, which in turn leads to a decrease in churning drag torque. 


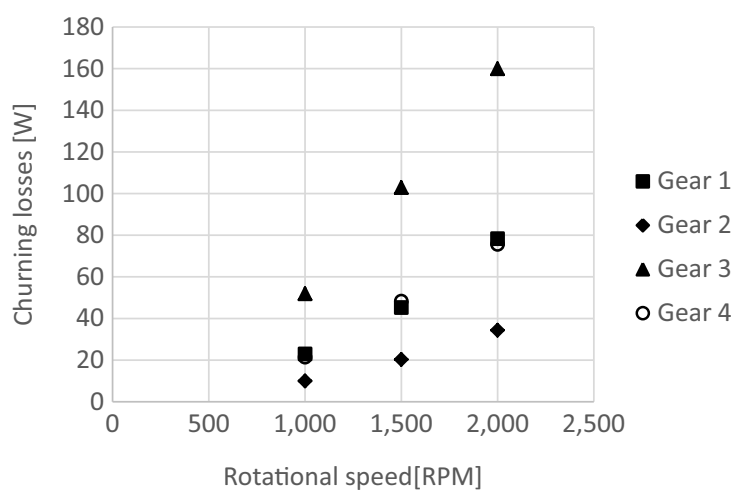

Fig. 5. Effect of rotational speed on churning losses measurements (oil C, $40^{\circ} \mathrm{C}, h / R=0.5$ ).

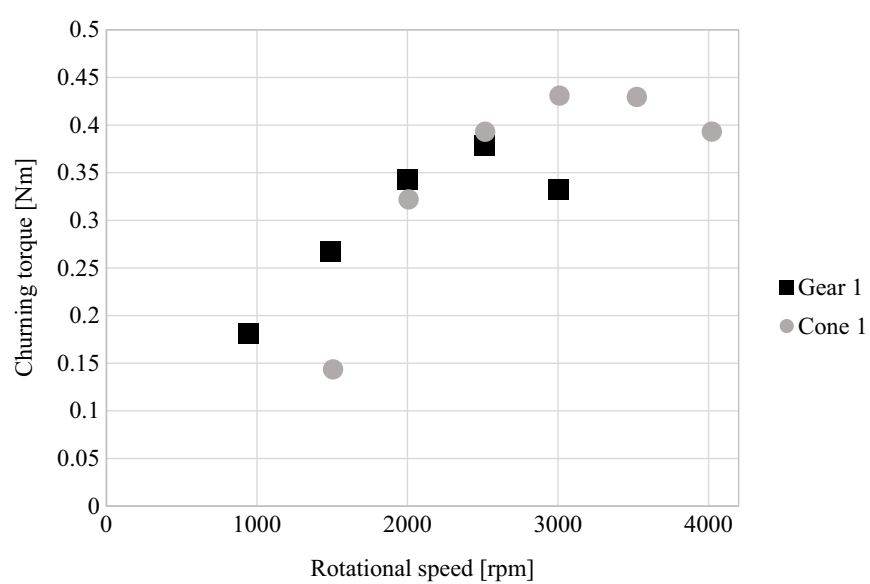

Fig. 6. Different regimes (oil B, $h / R=0.5,50^{\circ} \mathrm{C}$ ).

This phenomenon is also observed for a smooth cone. The present paper is focused on the first regime where the churning torque increases with speed.

To further investigate the influence of spiral bevel gear geometry more tests were performed. Figures 4 and 5 show that gears 1 and 4 have the same behaviour. These gears have a similar external diameter (roughly equals to $160 \mathrm{~mm}$ ) but present different tooth geometries (number of teeth, face width, face angle, etc.). In Figure 6, cone 1 and gear 1 have also a similar behaviour.

In Figure 7, cone 2 has a similar diameter than cone 1, but different face angle and width. As its behaviour is close to cone 1 and gear 1 it can be deduced that the external diameter appears as the main geometrical parameter, whereas the tooth influence can be neglected for the tested conditions.

Looking at the oil properties, Figure 8 presents churning losses generated by gear 3 versus oil viscosity for constant rotational speed and immersion depth. In order to analyse the influence of viscosity, the oil sump is heated using heating covers. Two flow regimes clearly emerge: for high values of viscosity, the churning torque decreases as viscosity is reduced whereas it remains constant for lower viscosity values. This behaviour has already been pointed out by Changenet et al. [17] for cylindrical gears.

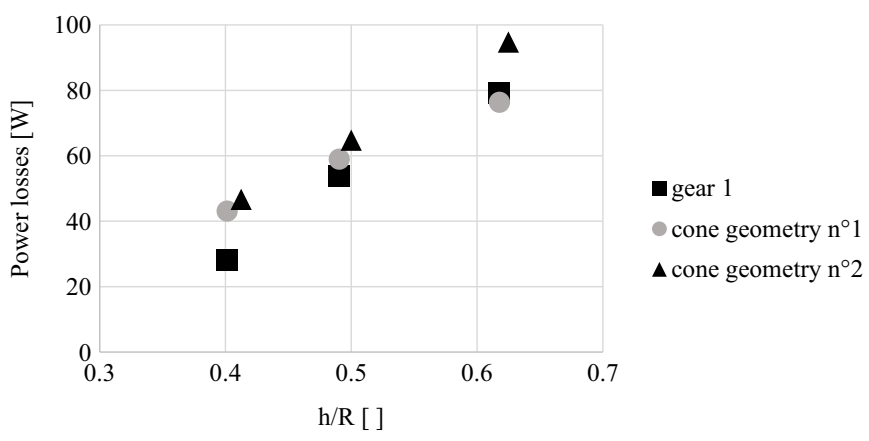

Fig. 7. Power losses for gear 1 and cones (oil D, $1500 \mathrm{rpm}, 40^{\circ} \mathrm{C}$ ).

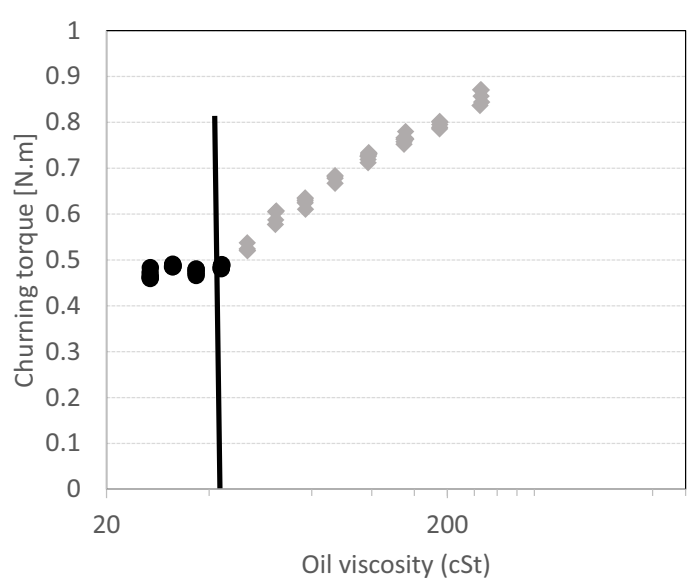

Fig. 8. Flow regimes (gear $3, h / R=0.6,1000 \mathrm{rpm}$ ).

As the published literature contains few calculation methods to estimate churning losses of bevel gears, some comparisons of the measured power loss with those predicted from the existing relationships have been done. As an example, Figure 9 presents churning losses generated by gear 3 as a function of speed. This figure highlights that power losses calculated with ISO/TR 14179-1 overestimate the measured ones. Indeed, according to this calculation method, the losses are proportional to $N^{3}$ which is not in accordance with experiments (proportional to $N^{1.7}$ ). Because of this discrepancy, ISO/TR 14179-1 is disregarded in the following analyses. In contrast, the churning loss levels given by ISO/TR 14179-2 and Jeon formula are closer from experimental results, even if some discrepancy is observed.

Another comparison, associated with the influence of oil properties, is given in Figure 10. As it has been underlined, two flow regimes clearly emerge from measurements whereas calculation methods are based on a single regime: the churning torque always decreases with viscosity according to Jeon's approach and it remains constant by using the relationships of ISO/TR 14179-2.

\section{Results analyses}

As spiral bevel gears macro-geometry is close to hypoid ones, the methodology used by Jeon [24] on hypoid gears was considered to further analyse experimental data. 


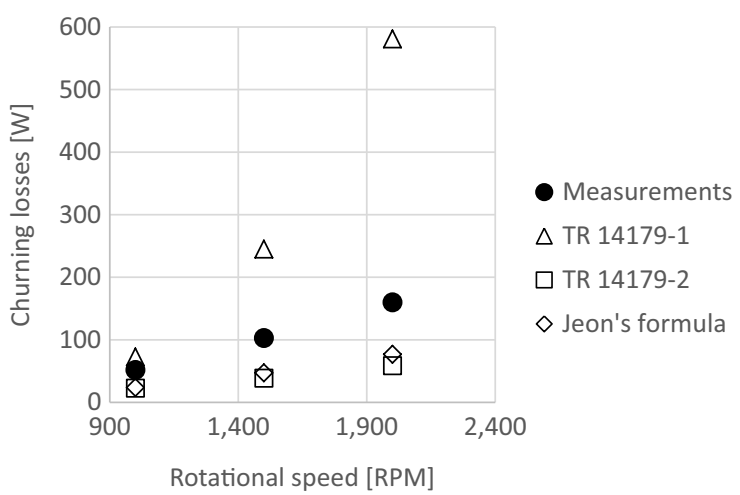

Fig. 9. Influence of speed on measured and calculated churning losses (gear 3 , oil $\mathrm{C}, 40^{\circ} \mathrm{C}, h / R=0.5$ ).

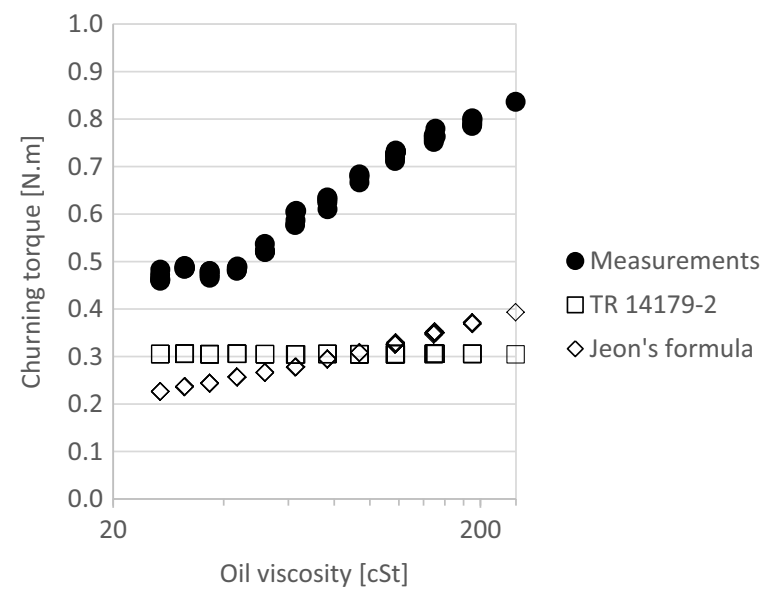

Fig. 10. Influence of oil properties on measured and calculated churning losses (gear 3, oil D, $h / R=0.6,1000 \mathrm{rpm}$ ).

Churning power losses are given by:

$$
P=\frac{1}{2} \rho \Omega^{3} R_{o}^{2} b S_{m} C_{m}
$$

where $\rho$ is the lubricant density, $\Omega$ is the rotational speed, $R_{o}$ is the outer radius on the large end of the bevel gear (see Fig. 3), $b$ is the width, $S_{m}$ is the submerged surface area and $C_{m}$ is the dimensionless drag torque expressed as follows:

$$
C_{m}=2.186\left[\frac{h}{R_{o}}\right]^{0.147}\left[\frac{V_{o}}{R_{o}^{3}}\right]^{-0.198} R^{-0.25} \mathrm{Fr}^{-0.53}
$$

where $h$ is gear immersion depth, $V_{o}$ the oil volume, $R e$ the Reynolds number and $\mathrm{Fr}$ the Froude number.

As experimental results have underlined that tooth geometry has a negligible influence on churning losses, the submerged surface area is quantified by modifying the cylindrical gear formula provided by Changenet et al. [17] and by only taking into account the equivalent envelope geometry of a spiral bevel gear. The detailed $S_{m}$ computation is presented in Appendix B. The analytical formula of $S_{m}$ concurs with Jeon's work on hypoid gears

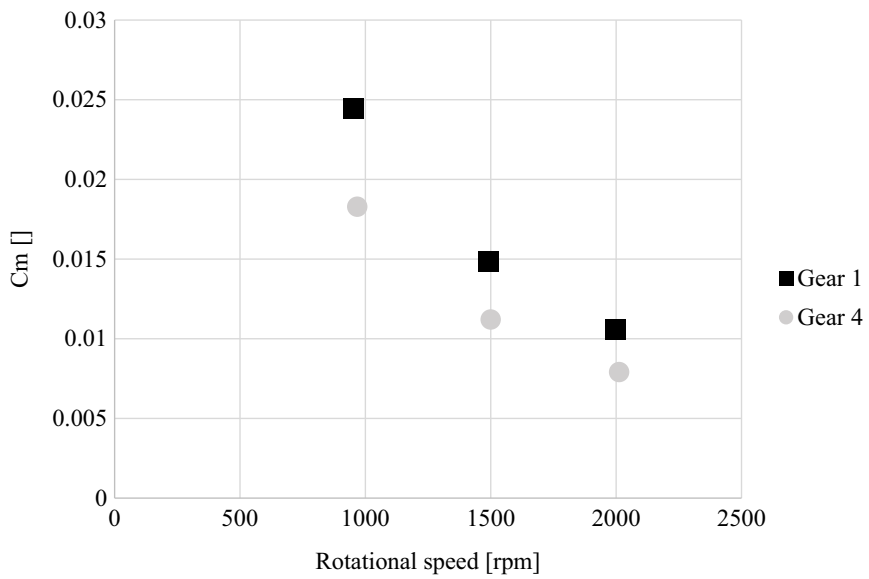

Fig. 11. $C_{m}$ for gears 1 and 4 according to equation (1) (oil B, $\left.70{ }^{\circ} \mathrm{C}, h / R=0.5\right)$.

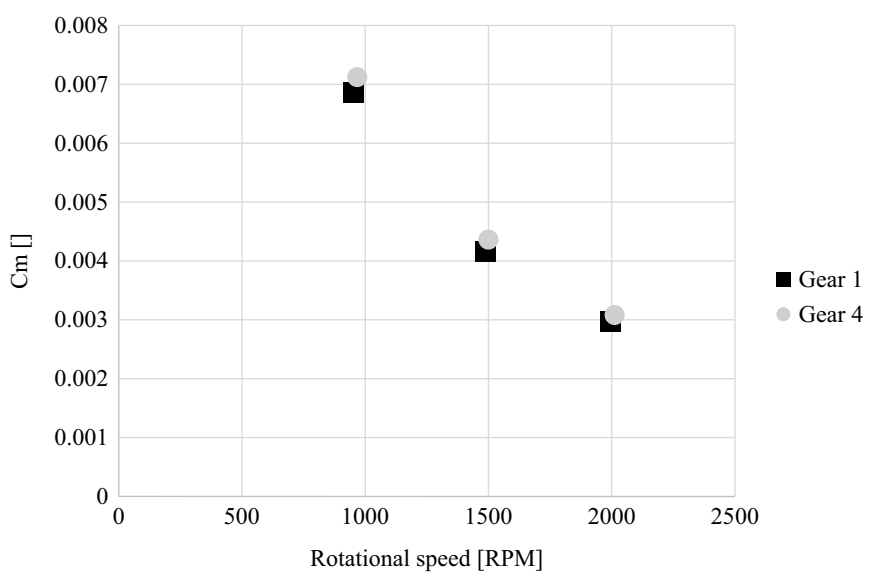

Fig. 12. $C_{m}$ for gears 1 and 4 according to equation (3) (oil B, $\left.70^{\circ} \mathrm{C}, h / R=0.5\right)$.

since the retained geometry is only related to the gear envelope dimensions. Then equation (1) can be used to determine experimental dimensionless churning torques from measurements. A typical series of results is presented in Figure 11. As gears 1 and 4 do not have identical values of $C_{m}$ but similar diameters, it can be deduced from dimensional analysis [26] that parameters associated with tooth geometry (module, tooth face width, etc.) have also to be taken into account to determine $C_{m}$, which is not in accordance with equation (2).

As the experiments show that the outer radius is a first order influent parameter, it is proposed to change equation (1) as follows:

$$
P=\frac{1}{2} \rho \Omega^{3} R_{o}^{3} S_{m} C_{m}
$$

Figure 12 demonstrates that this new relationship leads to identical dimensionless drag torque for gears 1 and 4 . It implies that the tooth geometry parameters are not to be taken into account anymore in dimensional analysis. 


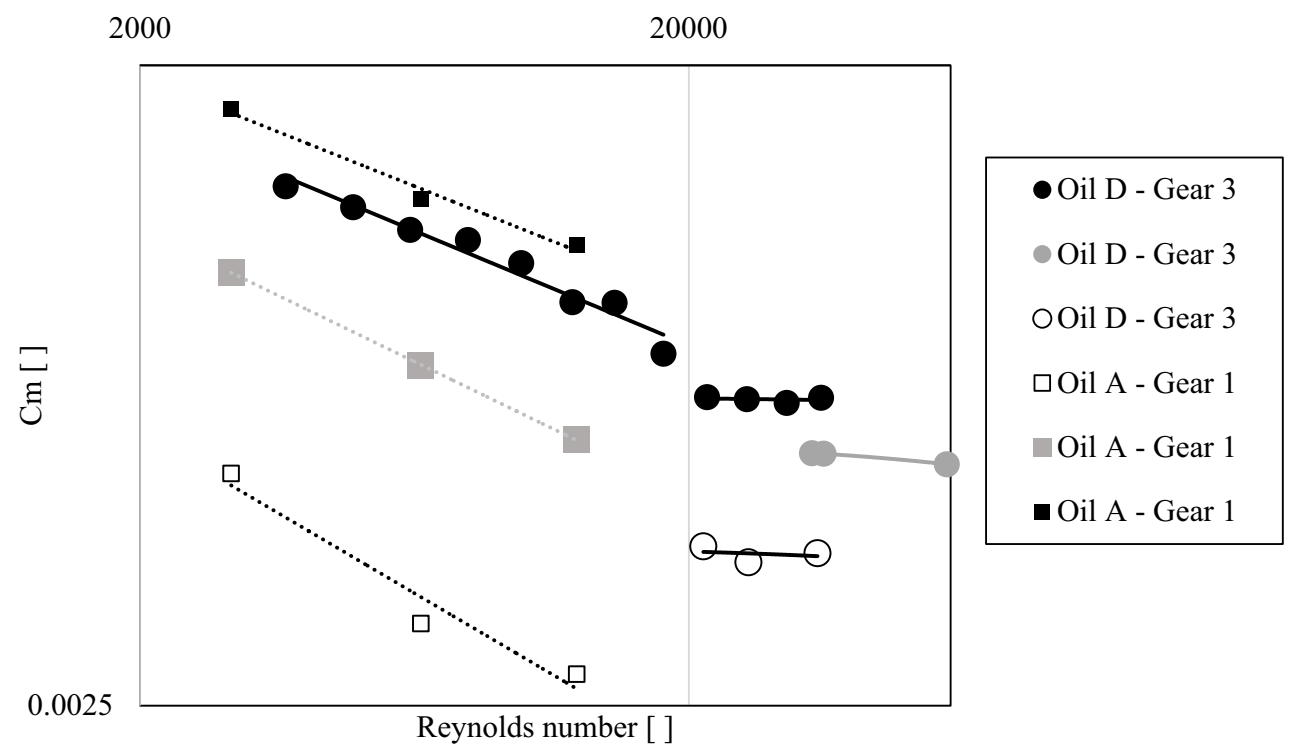

Fig. 13. Two flow regimes of churning depending on Reynolds number.

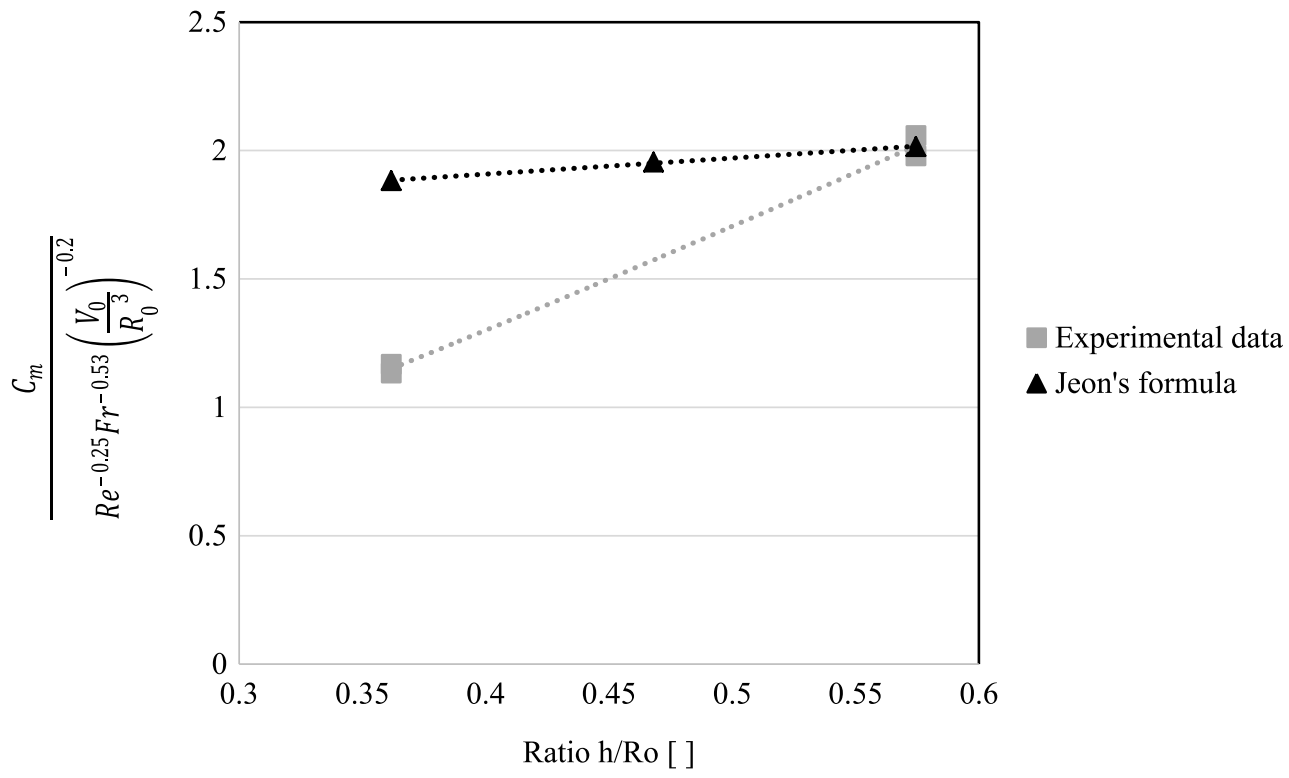

Fig. 14. $h / R$ influence (gear 3, $1000 \mathrm{rpm}$, oil D).

Nevertheless, influential parameters identified in equation (2) can be kept for a further analysis:

$$
C_{m}=\gamma_{1} \operatorname{Re}^{\gamma_{2}} \mathrm{Fr}^{\gamma_{3}}\left(\frac{h}{R_{o}}\right)^{\gamma_{4}}\left(\frac{V_{o}}{R_{o}^{3}}\right)^{\gamma_{5}}
$$

where $\gamma_{1}, \ldots, \gamma_{5}$ are constant coefficients which are adjusted from experimental results.

Figure 13 presents the dimensionless torque $C_{m}$ for two different gears (1 and 3 ) and two oils (A and D) according to the Reynolds number. The two flow regimes that have been pointed out in Section 4 clearly appear on this figure. A transition between the two flow regimes is observed for a
Reynolds number around 20000 . For the regime below the transition, $\gamma_{2}$ equals -0.25 (in agreement with Jeon's formula) whereas for higher Reynolds number, $\gamma_{2}$ is zero. For this last regime, it means that viscous forces become negligible.

Concerning the Froude number, its influence can be isolated through tests where only the rotational speed varies as the ones given in Figure 5. The constant $\gamma_{3}$ can then be deduced. A value of -0.53 is found which is identical to Jeon's formula.

As far as influence of gear immersion is concerned, equation (2) is used to determine the following ratio $\left(C_{m} /\left(\operatorname{Re}^{-0.25} \mathrm{Fr}^{-0.53}\left(V_{o} / R_{o}^{3}\right)^{-0.198}\right)\right)$ according to relative 


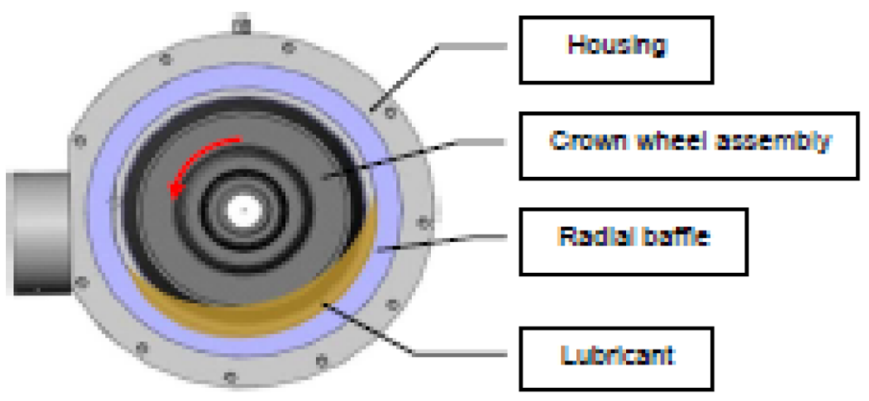

Fig. 15. Jeon test rig, oil behaviour during tests [extract of Jeon PhD illustration].

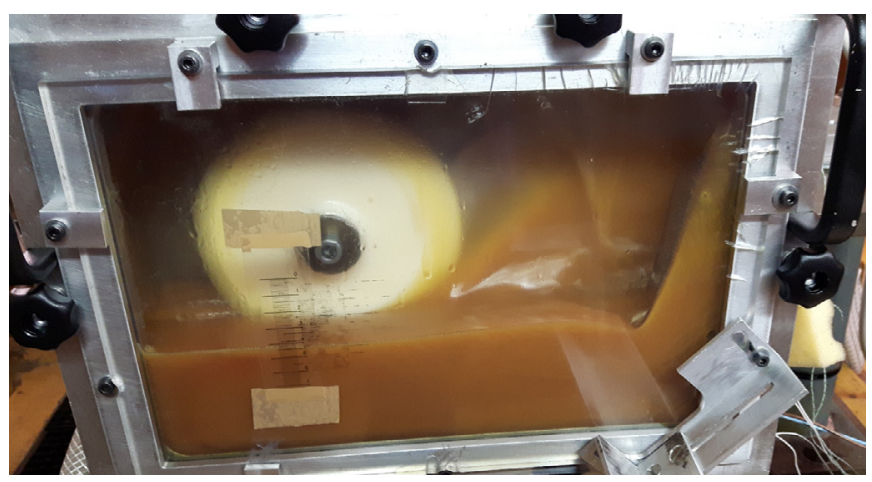

Fig. 16. Oil behaviour in ECAM test rig.

immersion depth $\left(h / R_{o}\right)$. In Figure 14 , this ratio is calculated in two different ways: either using experimental data for $C_{m}$ or using Jeon's relationship. It appears that comparing these two calculations, experiments lead to a more sensitiveness to the relative immersion depth. Looking at the general geometry of the casing in the Jeon's experiments (Fig. 15) and in the present study (Fig. 16) it can be noticed that the gears do not generate a similar oil flow probably due to enclosure effect. The axle housing presents a circular shape around the crown gear, contrary to this study where a parallelepiped defines the oil sump. In order to investigate this assumption, complementary tests were conducted with deflector around the bevel gear (Fig. 17). These tests (with and without a deflector) are reported in Figure 18 and show the impact of the housing on the dimensionless drag torque: adding a deflector modifies considerably the evolution of dimensionless torque according to the relative immersion. This is consistent with the observation mentioned previously.

\section{Conclusion}

Only few works deal with churning losses of bevel or hypoid gears. Moreover, the published literature contains different calculation methods to quantify this source of dissipation and these methods may give widely different results. In order to resolve the discrepancy, the authors have compared some experimental results with the predictions from various literature sources. It is shown that the results did not agree well with the predictions for all operating conditions, although correlation was somewhat better with

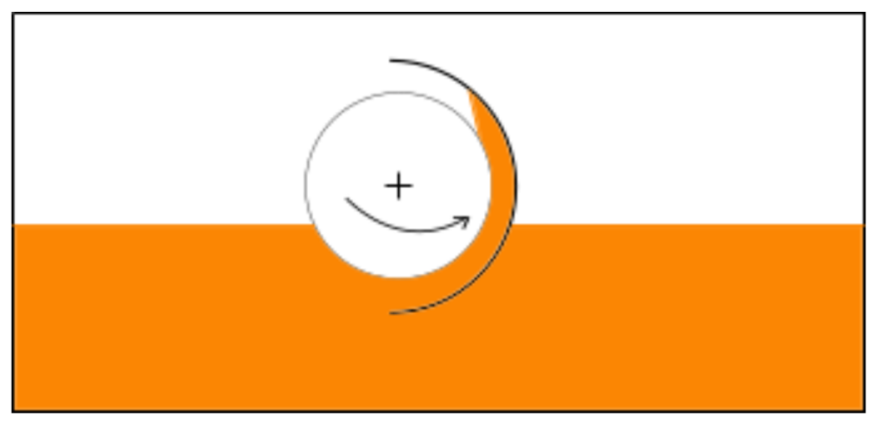

Fig. 17. Position of the deflector and direction of rotation of the gear.

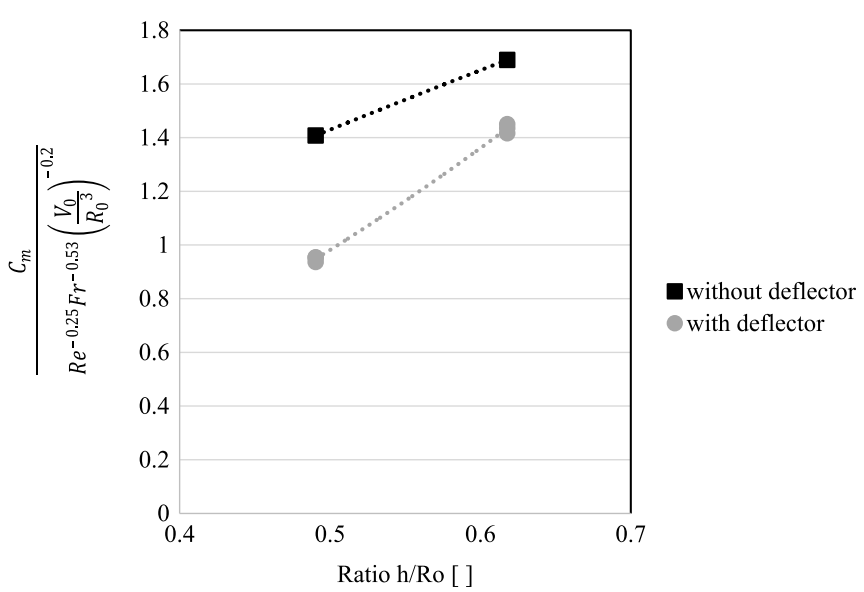

Fig. 18. Housing influence (gear $1,2000 \mathrm{rpm}$, oil D, $40^{\circ} \mathrm{C}$ ).

the predictions derived from Jeon's work. In order to extend Jeon's formula, numerous tests were conducted for different gear geometries and lubricants. To this end a specific test rig was used and the following conclusions can be addressed:

- two lubricant flow regimes appear according to the Reynolds number value (around 20000). For high Reynolds number, the viscosity has a negligible effect on churning losses whereas for lower values the observed behaviour is similar to the one pointed by Jeon;

- the main influential geometrical parameter is the external diameter of the bevel gear and other parameters such as module, tooth number and face width are of second order. To take into account this point, the dimensional analysis proposed by Jeon has been modified;

- a great discrepancy between the present tests and Jeon's formula was noticed concerning the influence of oil level. It was assumed that it was linked to the difference in terms of enclosure between the two tests rigs. Other tests were performed with movable walls and confirm this hypothesis.

The development of new relationships to estimate the churning losses generated by bevel gears aims to extend the validity range of Jeon's formula to different bevel gear geometries and several fluid flow regimes while it is clear from this study that a modelling methodology valid for all casing types and configurations is still required. 


\section{Nomenclature}

$A_{1} \quad$ area of the back end side of the cone, $\mathrm{m}^{2}$

$A_{2} \quad$ area of the front side of the cone, $\mathrm{m}^{2}$

$A_{3} \quad$ area of the peripheral surface of the cone, $\mathrm{m}^{2}$

$a, a^{\prime} \quad$ parameter of the equation of the slope of the peripheral surface, $a^{\prime}$ for immersed dimensions

$b, b^{\prime} \quad$ parameter of the equation of the slope of the peripheral surface ; $b^{\prime}$ for immersed dimensions, $\mathrm{m}$

$C_{m} \quad$ dimensionless drag torque

$e_{o} \quad$ radius of the front side of the truncated cone $\Omega^{2} R \quad$ associated to the cone of base radius $R_{o}, \mathrm{~m}$

$F r=\frac{\Omega^{2} R_{o}}{g} \quad$ Froude number depending on gear parameters

$g \quad$ acceleration of gravity, $\mathrm{m} \mathrm{s}^{-2}$

$H \quad$ height of the tooth, m

$h \quad$ immersion depth of a pinion, $m$

$h^{*}=R_{o}-h \quad$ difference between the radius and the immersion depth, m

$N \quad$ rotational speed, rpm

$P \quad$ churning power losses, W

$R e=\frac{\Omega R_{o}^{2}}{v} \quad$ Reynolds number

$R_{o} \quad$ outer radius, $\mathrm{m}$

$S_{m} \quad$ immersed surface area of the pinion, $\mathrm{m}^{2}$

$V_{o} \quad$ oil volume, $\mathrm{m}^{3}$

$\alpha \quad$ pressure angle, rad

$\gamma_{i} \quad$ power law coefficient $i$

$\theta \quad$ angle associated to the immersed surface of

$\lambda$ the circular base of the cone, rad

$\lambda \quad$ test number $\lambda$

$\Phi \quad$ test number $\Phi$

$v \quad$ kinematic viscosity, $\mathrm{m}^{2} \mathrm{~s}^{-1}$

$\rho \quad$ fluid density, $\mathrm{kg} \mathrm{m}^{-3}$

$\psi \quad$ spiral angle, rad

$\Pi_{i} \quad$ dimensionless parameter number $i$

$\Omega \quad$ angular velocity, $\operatorname{rad~s}^{-1}$

\section{Appendices}

\section{Appendix A Churning losses formulas (a) ISO/TR 14179-1 [22]}

Churning power losses are decomposed as the sum of the ones associated with the faces of the gear $\left(P_{\text {sides }}\right)$ and the ones of the tooth surfaces $\left(P_{\text {tooth }}\right)$.

For the faces of the gear:

$$
P_{\text {sides }}=\frac{1.474 \cdot f_{g} \cdot v \cdot n^{3} \cdot D^{5.7}}{A_{g} \cdot 10^{26}}
$$

For tooth surfaces:

$$
P_{\text {tooth }}=\frac{7.37 \cdot f_{g} \cdot v \cdot n^{3} \cdot D^{4.7} \cdot F \cdot\left(\frac{R_{f}}{\sqrt{\tan (\beta)}}\right)}{A_{g} \cdot 10^{26}}
$$

$R_{f}$ is the roughness factor which is defined as:

$$
R_{f}=7.93-\frac{4.648}{m_{t}}
$$

where $P_{i}$ is the power loss for each individual element $[\mathrm{kW}$, $f_{g}$ is the gear dip factor $\left(0 \leq f_{g} \leq 1\right), v$ is the kinematic viscosity of the oil at operating temperature [cSt], $m_{t}$ is the transverse tooth module, $D$ is the outside diameter of the gear $[\mathrm{mm}], A_{g}$ is the arrangement constant $(=0.2), F$ is the total face width [mm], $\beta$ is the generated helix angle $\left[^{\circ}\right.$ (if $\beta<10^{\circ}$ then consider $\left.\beta=10^{\circ}\right), n$ is the rotational speed $[\mathrm{rpm}]$.

\section{(b) ISO-TR 14179-2 [23]}

The churning loss is expressed as:

$$
\begin{gathered}
P=T_{H} \cdot \omega \\
T_{H}=C_{s p} \cdot C_{1} \cdot e^{C_{2}\left(v_{t} / v_{t 0}\right)}
\end{gathered}
$$

where $\omega$ is the rotational speed $\left[\mathrm{rad} \mathrm{s}^{-1}\right], T_{H}$ is the churning torque $[\mathrm{Nm}], v_{t}$ is the peripheral speed at pitch circle $\left[\mathrm{ms}^{-1}\right]$ and $v_{t 0}=10 \mathrm{~m} \mathrm{~s}^{-1}$.

The other factors are determined by the following relationships:

$$
\begin{gathered}
C_{s p}=\left(\frac{4 \cdot h_{e \max }}{3 \cdot h_{c}}\right)^{1.5} \frac{2 \cdot h_{c}}{l_{h}} \\
C_{1}=0.063\left(\frac{h_{e 1}+h_{e 2}}{h_{e 0}}\right)+0.0128\left(\frac{b}{b_{0}}\right)^{3} \\
C_{2}=\frac{h_{e 1}+h_{e 2}}{80 \cdot h_{e 0}}+0.2
\end{gathered}
$$

where $h_{e 1}$ and $h_{e 2}$ are the tip circle immersion depths with oil level stationary $[\mathrm{mm}], h_{e 0}$ is the reference value of immersion depth $(=10 \mathrm{~mm}), h_{c}$ is the height of point of contact above the lowest point of the immersing gear [mm], $l_{h}$ is the hydraulic length [mm], $b$ is the tooth width [mm] and $b_{0}=10 \mathrm{~mm}$.

As far as the hydraulic length is concerned, it is calculated by:

$$
l_{h}=4 \cdot \frac{A_{G}}{U_{M}}
$$

where $A_{G}$ is the enclosure area, $U_{M}$ is the enclosure circumference.

\section{(c) Jeon PhD work [24]}

In this approach, power losses are expressed as a function of a dimensionless drag torque which in turn depends on several non-dimension numbers. Detailed equations are given in Section 5. 


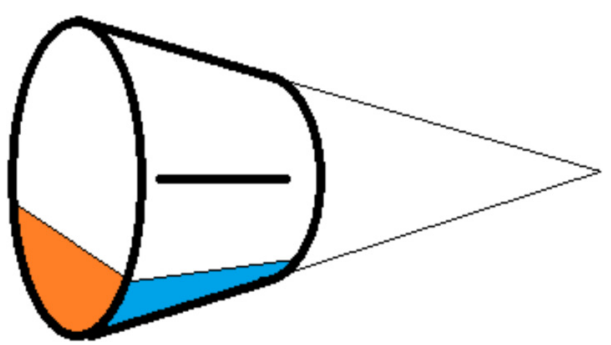

Fig. 19. Scheme from the back side of the pinion (tooth not represented), with the cone angle.

\section{Appendix B Submerged surface area $S_{m}$ formula}

The immersed areas of a bevel gear are identified in Figure 19.

To simplify the problem, two areas are isolated: the front and back areas $\{a\}$, the peripheral area $\{b\}$.

\section{(a) The front and back areas (orange areas in Fig. 19)}

The areas are computed as follows for the front and back side of the gear:

$-h^{*}$ is defined as a constant value computed from the back end of the gear:

$$
h^{*}=R_{o}-h
$$

- Then, the orange area for the back side is:

$$
A 1=\frac{1}{2} R_{o}^{2}\left(2 a \cos \left(\frac{h^{*}}{R_{o}}\right)-\sin \left(2 a \cos \left(\frac{h^{*}}{R_{o}}\right)\right)\right)
$$

For the front side, it is:

$$
A 2=\frac{1}{2} e_{o}^{2}\left(2 a \cos \left(\frac{h^{*}}{e_{o}}\right)-\sin \left(2 a \cos \left(\frac{h^{*}}{e_{o}}\right)\right)\right)
$$

$e_{o}$ represents the radius of the front side of the truncated cone associated to the cone of base radius $R_{o}$.

\section{(b) The peripheral area}

It represents the area of the side face of the truncated cone which is immersed in the lubricant sump. It is coloured in blue in Figure 19. A function shown in Figure 20 is defined which represents the slope of the external surface.

$b^{\prime}$ is equal to zero so $a^{\prime}$ is defined. $\theta_{\max }$ is set as:

$$
\theta_{\max }=a \cos \left(\frac{h^{*}}{R_{o}}\right)
$$

From Figure 20 and these notations, the area of the external surface of the cone of radius $R_{o}$ is expressed as:

$$
A 3=\int_{a}^{a+b} 2 \theta(x) r(x) \mathrm{d} x
$$

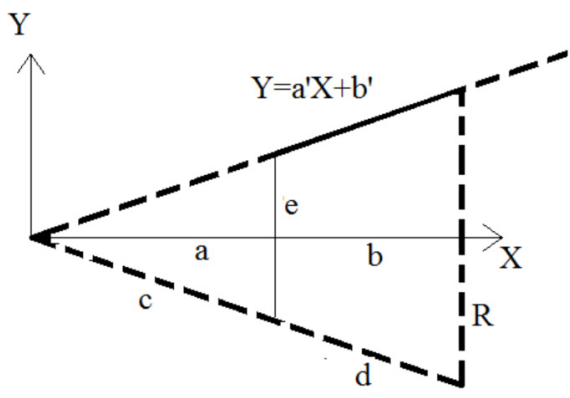

Fig. 20. Function representing the slope of external surface.

Finally the area is equal to:

$$
\begin{array}{r}
A 3=\left[( a + b ) \left(a^{\prime}(a+b) a \cos \left(\frac{h^{*}}{a^{\prime}(a+b)}\right)\right.\right. \\
\left.-H \sqrt{\left.1-\frac{h^{* 2}}{a^{\prime 2}(a+b)}\right)}\right] \\
-\left[a\left(a^{\prime} a \cos \left(\frac{h^{*}}{a^{\prime} a}\right)-H \sqrt{1-\frac{h^{* 2}}{a^{\prime 2} a^{2}}}\right)\right]
\end{array}
$$

$H$ is the height of the tooth.

\section{References}

[1] P. Luke, A.V. Olver, A study of churning losses in diplubricated spur gears, Proc. Inst. Mech. Eng. G J. Aerosp. Eng. 213 (1999) 337-346

[2] A.S. Kolekar, A.V. Olver, A.E. Sworski, F.E. Lockwood, The efficiency of a hypoid axle - a thermally coupled lubrication model, Tribol. Int. 59 (2013) 203-209

[3] S.L. Soo, N.J. Princeton, Laminar flow over an enclosed rotating disk, Trans. ASME 80 (1958) 287-296

[4] J.W. Daily, R.E. Nece, Chamber dimension effects on induced flow and frictional resistance of enclosed rotating disks, J. Basic Eng. 82 (1960) 217-230

[5] R.W. Mann, C.H. Marston, Friction drag on bladed disks in housings as a function of Reynolds number, axial and radial clearance, and blade aspect ratio and solidity, J. Basic Eng. 83 (1961) 719-723

[6] A.S. Terekhov, Hydraulic losses in gearboxes with oil immersion, Vestn. Mashinostroeniya 55 (1975) 13-17

[7] E. Lauster, M. Boos, Zum wärmehaushalt mechanischer schaltgetriebe für nutzfahrzeuge, VDI-Berichte (1983) 45-55

[8] R. Boness, Churning losses of discs and gears running partially submerged in oil, in: Proc. ASME Int. Power Trans. Gearing Conf., vol. 1, 1989, pp. 255-359

[9] P. Walter, Anwendungsgrenzen fuer die tauchschmierung von zahnradgetrieben, plansch- und quetschverluste bei tauchschmierung, Forschungsheft, Forschungsvereinigung Antriebstechnik, 1982

[10] W. Mauz, Hydraulische Verluste von Stirnradgetrieben bei Umfangsgeschwindigkeiten bis $60 \mathrm{~m} / \mathrm{s}$, Berichte des Institutes für Maschinenkonstruktion und Getriebebau, IMK, 1987

[11] B. Höhn, K. Michaelis, T. Vollmer, American Gear Manufacturers Association, Thermal rating of gear drives balance between power loss and heat dissipation. Technical papers, American Gear Manufacturers Association, 1996 
[12] B. Höhn, K. Michaelis, H. Otto, Influence on no-load gear losses, in: Proceedings of the Ecotrib 2011 Conference, Vienna, Austria, vol. 2, 2011, pp. 639-644

[13] S. Seetharaman, A. Kahraman, M.D. Moorhead, T.T. PetryJohnson, Oil churning power losses of a gear pair: experiments and model validation, J. Tribol. 131 (2009) 022202

[14] H. Arisawa, M. Nishimura, H. Imai, T. Goi, Computational fluid dynamics simulations and experiments for reduction of oil churning loss and windage loss in aeroengine transmission gears, J. Eng. Gas Turbines Power 136 (2014) 092604

[15] A.S. Kolekar, A.V. Olver, A.E. Sworski, F.E. Lockwood, Windage and churning effects in dipped lubrication, J. Tribol. 136 (2014) 021801

[16] C. Changenet, P. Velex, Housing influence on churning losses in geared transmissions, J. Mech. Des. 130 (2008) 0626031-0626036

[17] C. Changenet, G. Leprince, F. Ville, P. Velex, A note on flow regimes and churning loss modeling, J. Mech. Des. 133 (2011) 121009

[18] P.M.T. Marques, C.M.C.G. Fernandes, R.C. Martins, J.H.O. Seabra, Efficiency of a gearbox lubricated with wind turbine gear oils, Tribol. Int. 71 (2014) 7-16

[19] F. Concli, C. Gorla, A. Della Torre, G. Montenegro, Churning power losses of ordinary gears: a new approach based on the internal fluid dynamics simulations, Lubr. Sci. 27 (2015) 313-326
[20] F. Concli, A.D. Torre, C. Gorla, G. Montenegro, A new integrated approach for the prediction of the load independent power losses of gears: development of a mesh-handling algorithm to reduce the CFD simulation time, Adv. Tribol. 2016 (2016) Article ID 2957151

[21] F. Concli, C. Gorla, K. Stahl, B.-R. Höhn, K. Michaelis, H. Schultheiß, J.-P. Stemplinger, Load independent power losses of ordinary gears: numerical and experimental analysis, in: Proceedings of 5th World Tribology Congress, WTC 2013, Torino, Italy, vol. 2, 2013, pp. 1243-1246

[22] ISO/TR 14179-1: Gears - thermal capacity; part 1: rating gear drives with thermal equilibrium at $95{ }^{\circ} \mathrm{C}$ sump temperature, 2001, p. 38

[23] ISO/TR 14179-2: Gears - thermal capacity; part 2: thermal load-carrying capacity, 2001, p. 42

[24] S.I. Jeon, Improving efficiency in drive lines: an experimental study on churning losses in hypoid axle, $\mathrm{PhD}$ thesis, Imperial College, London, 2010

[25] G. LePrince, C. Changenet, F. Ville, P. Velex, C. Dufau, F. Jarnias, Influence of aerated lubricants on gear churning losses - an engineering model, Tribol. Trans. 54 (2011) 929-938

[26] T. Misic, M. Najdanovic-Lukic, L. Nesic, Dimensional analysis in physics and the Buckingham theorem, Eur. J. Phys. 31 (2010) 893

Cite this article as: S. Laruelle, C. Fossier, C. Changenet, F. Ville, S. Koechlin, Experimental investigations and analysis on churning losses of splash lubricated spiral bevel gears, Mechanics \& Industry 18, 412 (2017) 